\title{
Shared epithelial pathways to lung repair and disease
}

\author{
Magda Spella ${ }^{1}$, Ioannis Lilis ${ }^{1}$ and Georgios T. Stathopoulos ${ }^{1,2}$
}

Affiliations: 'Laboratory for Molecular Respiratory Carcinogenesis, Dept of Physiology, Faculty of Medicine, University of Patras, Rio, Greece. ${ }^{2}$ Comprehensive Pneumology Center and Institute for Lung Biology and Disease, University Hospital, Ludwig-Maximilians University and Helmholtz Center Munich, Member of the German Center for Lung Research (DZL), Munich, Germany.

Correspondence: Georgios T. Stathopoulos, Laboratory for Molecular Respiratory Carcinogenesis, Dept of Physiology, Faculty of Medicine, University of Patras, Basic Biomedical Sciences Building, 2nd Floor, Room B40, 1 Asklepiou Str., University Campus, 26504 Rio, Greece. E-mail: gstathopdupatras.gr

$@$ ERSpublications

Cells with regenerative potential are implicated in obstructive, fibrotic and neoplastic lung diseases http://ow.ly/YH7930c00Fz

Cite this article as: Spella M, Lilis I, Stathopoulos GT. Shared epithelial pathways to lung repair and disease. Eur Respir Rev 2017; 26: 170048 [https://doi.org/10.1183/16000617.0048-2017].

ABSTRACT Chronic lung diseases present tremendous health burdens and share a common pathobiology of dysfunctional epithelial repair. Lung adenocarcinoma, the leading cancer killer worldwide, is caused mainly by chemical carcinogens of tobacco smoke that induce mutations in pulmonary epithelial cells leading to uncontrolled epithelial proliferation. Lung epithelial cells that possess the capacity for selfrenewal and regeneration of other lung cell types are believed to underlie the pathobiology of chronic obstructive, fibrotic and neoplastic lung disorders. However, the understanding of lung epithelial progenitor cell hierarchy and turnover is incomplete and a comprehensive model of the cellular and transcriptional events that underlie lung regeneration and carcinogenesis is missing. The mapping of these processes is extremely important, since their modulation would potentially allow effective cure and/or prevention of chronic lung diseases. In this review we describe current knowledge on cellular and molecular pathways at play during lung repair and carcinogenesis and summarise the critical lung cell populations with regenerative and cancerous potential.

\section{Introduction}

Lung cancer, chronic obstructive pulmonary disease (COPD) and lower respiratory infections causing septic and fibrotic sequelae were among the top five leading causes of death in the 2010 Global Burden of Disease study [1], claiming altogether $>7$ million lives in that year. The epidemic of lung cancer appears to be on a continuous rise, despite smoking prevention and cessation programmes, as evident from its global death toll in 2012 and the comparative 2005-2015 trends in the Global Burden of Disease cancer network study $[2,3]$. Human lung cancers are typed into two main histopathological groupings which, in addition, reflect treatment response and prognosis: small cell lung cancer and nonsmall cell lung cancer (NSCLC). NSCLC, including mainly adenocarcinoma and squamous cell carcinoma, accounts for $\sim 80-85 \%$ of lung cancer cases, and adenocarcinoma, its main subtype, increasingly affects current, ex- and even

Received: April 122017 | Accepted after revision: May 192017

Support statement: Research funding was received from the European Research Council (Starting Independent Investigator Grant, number 260524, and Proof of Concept Grant, number 679345, to G.T. Stathopoulos) and the Hellenic State Scholarships Foundation (IKY; Research Fellowship 2014 to M. Spella). Funding information for this article has been deposited with the Crossref Funder Registry.

Conflict of interest: None declared.

Provenance: Commissioned article, peer reviewed.

Copyright CERS 2017. ERR articles are open access and distributed under the terms of the Creative Commons Attribution Non-Commercial Licence 4.0. 
never-smokers [4-6]. Chronic lung diseases, such as COPD and idiopathic pulmonary fibrosis (IPF) are generally accepted to arise from chronic epithelial injury and incomplete or aberrant repair processes [7-11]. In contrast, lung cancer is caused by tobacco chemical-induced mutations in pulmonary epithelial cells, leading to uncontrolled cellular proliferation [12-14]. Despite significant efforts, it is still unclear whether the primary lesions of chronic obstructive, fibrotic and neoplastic disorders occur in the airways, the alveoli or both epithelial compartments, while cells with repair potential occur in large and small airways, as well as alveoli [15-20]. Although the alveoli execute the main function of the lungs, i.e. gas exchange, multiple lines of evidence indicate that the primary pathogenic abnormalities of chronic obstructive, fibrotic and neoplastic disorders can also occur in the airways, in addition to the alveoli $[10,11,21,22]$. In addition, lineage-specific genes encoding epithelial proteins that support the physiological functions of the lungs were recently shown to suffer noncoding insertions and deletions in lung adenocarcinoma, lending further support to the longstanding notion that epithelial cells that express lung-restricted proteins are the cellular sources of lung cancer [23]. Collectively, the available evidence indicates that the same lung epithelial cells that maintain the lungs in adulthood and are responsible for their repair after injury are the culprits in chronic lung diseases and cancer.

\section{Lung cells with regenerative potential}

The identification of lung cellular populations with repair and renewal capacities has been an area of intense investigation and has yielded several candidate stem/progenitor cell lineages confined to spatially distinct compartments of the pulmonary epithelium that express discrete markers. Notably, most of our knowledge on the cellular hierarchy of the lung epithelium and the relative contributions of each epithelial cell lineage to lung homeostasis after injury stems from studies on mouse models. In the mouse, airway stem cell niches have been identified in tracheal submucosal gland ducts, neuroendocrine bodies (NEB) and the broncholalveolar duct junction (BADJ), the region where the airways transition into alveoli [24-29]. The epithelium of the large airways consists of ciliated cells effecting mucociliary clearance and expressing acetylated tubulin 1A1 and the transcription factor FOXJ1, club cells secreting thin mucus and expressing club cell secretory protein (also known as club cell $10-\mathrm{kDa}$ protein, encoded by secreted uteroglobin 1a1 (Scgb1a1)), goblet cells secreting thick (viscous) mucus and expressing mucins 5A-5C, neuroendocrine cells organised in NEBs expressing neural differentiation markers and basal cells expressing transformation-related protein-63 and cytokeratins-5 and/or - 14 . The epithelium of smaller airways contains club, ciliated and neuroendocrine cells, while the BADJ consists mainly of club cells and cells with dual club/alveolar type II (ATII) properties called bronchoalveolar stem cells (BASCs) [19]. The alveolar epithelium is composed of alveolar type (ATI) cells adapted for optimal gas exchange and ATII cells, the main producers of surfactant proteins A-D and the stem cells of the distal lung [16, 23, 24]. Proximal airways as well as the distal bronchioles of the human lung are lined by a pseudostratified epithelium containing basal, secretory (club and goblet), ciliated and neuroendocrine cells, while human alveoli, like those in mouse lungs, are comprised of ATI and ATII cells [30-32]. For obvious reasons, not many studies investigating human lung stem cells exist. However, accumulating evidence suggests that basal cells could represent a multipotent population of stem cells, sustaining human lung homeostasis and probably contributing to disease susceptibility [31,33]. Furthermore, an important role for ATII cells in human alveolar maintenance and repair has been proposed [15].

\section{Cellular pathways to lung repair, disease and cancer}

The lungs constitute the body's largest interface with the external environment. The $\sim 90 \mathrm{~m}^{2}$ of alveolar surface area of a resting adult come in contact with and filter $>10 \mathrm{~m}^{3}$ of ambient air on a daily basis to sustain gas exchange. Hence, stochastic and repetitive environmental noxious stimuli including tobacco-contained and other chemicals, bacterial or viral pathogens, inhaled particles, home pneumotoxins, etc. continuously insult the lungs, even during unchallenged ageing. In addition to this background of everyday hits, the lungs sustain massive insults that ensue sporadically in cases of infection, aspiration, sepsis and other acute lung injuries. Lung stem/progenitor cells, including bronchial and alveolar epithelial cells, physiologically display sufficient repair and renewal capacity and phenotypic plasticity to maintain lung structure and function in response to chronic and acute noxious stimuli.

In the mouse lung, resting-state homeostasis is achieved mainly via self-renewal and concomitant generation of heterotypic lung cells from basal, club, BASC and ATII cells. It has been shown that basal cells can give rise to ciliated and club cells $[26,28]$. Club cells maintain their own population and replenish ciliated cells, and as such maintain the bronchiolar epithelial structural and functional integrity $[27,28]$, while ATII cells are able to self-renew and give rise to ATI cells $[15,16]$.

How are cellular dynamics altered upon acute and more extensive lung injury? Airway epithelial regeneration has been widely studied after naphthalene injury in mice, which selectively depletes the vast majority of club cells. These studies demonstrated that damaged airways are regenerated by a small, variant 
club cell population adjacent to NEBs and in the BADJs, which is resistant to naphthalene toxicity and expands post-injury to replenish the damaged airways $[17,18]$. Furthermore, BASCs were shown to possess bronchial regenerative potential post-naphthalene injury [19,34]. An exciting notion proposed by TATA et al. [35] is that $S c g b l a 1^{+}$cells can de-differentiate to give rise to basal cells. After lung injury, goblet cells are replenished by $S c g b 1 a 1^{+}$cells, but they might also derive from ciliated Foxj $1^{+}$cells, albeit to a lesser extent [36, 37]. Conversely, ATII cells are considered to be the main cellular population regenerating the alveolar compartment, able to give rise to both ATI and ATII cells after alveolar damage induced by bleomycin [15], conditional expression of diphtheria toxin by alveolar cells [15] or hyperoxia $[16,27]$. However, studies describe an emerging role for $S c g b l a 1^{+}$club cells in the regeneration of both ATI and ATII cells following severe bleomycin-mediated injury [29]. In line with these observations, unpublished data of the authors support that distal alveolar epithelium is enriched in Scgbla1 ${ }^{+}$cells after bleomycin- and hyperoxia-induced lung injury, in accordance with previous findings [38, 39], as well as during unchallenged ageing. Whether these distally located, regenerating Scgb1a1 ${ }^{+}$cells are due to the expansion of a distal basal cell population or to the activation of airway phenotypic markers in distal alveolar stem cells or to an actual migration of bronchial epithelial cells from the proximal airways remains to be investigated.

In chronic obstructive, fibrotic and neoplastic lung disorders, the normal balance of pulmonary cell death (injury) and life (repair) is tilted towards disease, manifested by the insufficiency of the lungs to perform gas exchange. The greatest evidence that chronic obstructive, fibrotic and neoplastic lung disorders are the result of abnormal epithelial homeostasis in response to chronic and acute environmental stress is their association with age [40] and smoking (figure 1). Interestingly, evidence suggests the implication of airway cells in human alveolar diseases. Indicatively, the pathogenesis of IPF has been associated with deregulated expression of MUC5B, a marker of goblet airway epithelial cells [22]. In patients with IPF, it has been suggested that regeneration of the fibrotic lung may be partly mediated by distal bronchial club or basal cells [9]. Furthermore, there is evidence that the emphysematous destruction in COPD is associated with narrowing and loss of terminal bronchioles [11].

The identification of lung cellular populations with stem cell characteristics has provided a valuable tool in the dissection of the underlying mechanisms of lung carcinogenesis, since stemness and oncogenic signalling in lung adenocarcinoma-initiating cells were shown to collide and to be druggable [41]. As the leading cancer killer worldwide, lung adenocarcinoma is caused mainly by chemical carcinogens in tobacco smoke that induce mutations in multiple genes of various distal pulmonary cells [12, 13], several pulmonary lineage tracing studies utilising targeted expression of oncogenes in the respiratory epithelium have been performed. However, despite considerable efforts, no definitive answer exists yet, as these studies incriminated different cells as progenitors of lung adenocarcinoma in adult mice: airway epithelial cells including basal and club cells, ATII cells and/or BASCs with dual ATII/club properties [16, 19, 20, 42-45]. In fact, new insights suggest that the molecular signature, like KRAS mutation or Sox2, Notch and Lkb1 signalling, is a crucial factor determining the cellular origin of cancer [46-48]. Similar studies on mouse

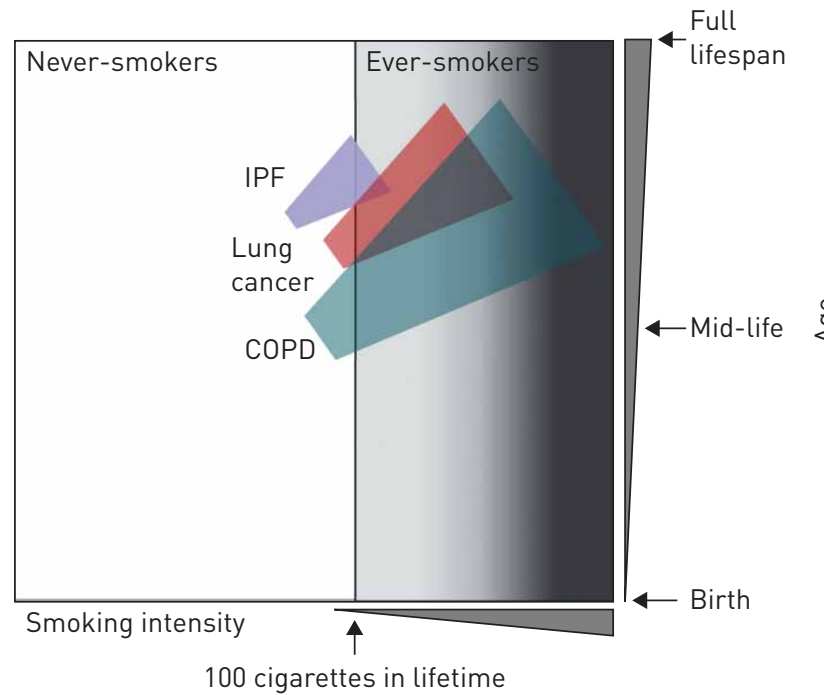

FIGURE 1 Schematic illustration of approximate overlap of smoking with chronic obstructive pulmonary disease (COPD), idiopathic pulmonary fibrosis (IPF) and lung cancer, drawn based on data from [1-3, 7, 8, 40]. 
models of lung squamous cell carcinoma have validated the oncogenes identified by human sequencing studies as causative of the disease, but have not yet unequivocally identified the cellular basis of the disease, even though basal cells are an attractive candidate [24, 49].

Importantly, recent studies suggest that the mutational landscape of human lung adenocarcinoma is closely mirrored by tobacco carcinogen-induced murine lung tumours, and not by lung cancers triggered by transgenic expression of oncogenic $K R A S^{\mathrm{G} 12 \mathrm{C}}$ or $K R A S^{\mathrm{G} 12 \mathrm{D}}$ mutations in the respiratory epithelium [14]. To this end, we have used chemical carcinogens contained in tobacco smoke in order to inflict lung adenocarcinoma in mice, in conjunction with accurate mouse models of continuous respiratory epithelial cell marking. Our unpublished results support an important role for the airway transcriptional signature in the development of lung adenocarcinoma, as we detected both airway and alveolar gene expression signatures in tobacco chemical-induced lung adenocarcinomas of mice.

\section{Molecular signalling events in the injured and precancerous lung}

Lung adenocarcinoma and squamous cell carcinoma have been associated with mutations, overexpression or loss of function of specific genes in distinct molecular pathways [13, 24, 25]. For example, indicative genes involved in squamous cell carcinoma include sex-determining region Y-box 2 (SOX2), fibroblast growth factor receptor 1 (FGFR1), phosphatase and tensin homologue (PTEN), cyclin-dependent kinase inhibitor 2A (CDKN2A), tumour protein 53 (TP53), and many more [50], while human adenocarcinomas have been associated with mutations in the Kirsten rat sarcoma viral oncogene homologue (KRAS), epidermal growth factor receptor $(E G F R)$, and v-Raf murine sarcoma viral oncogene homologue B $(B R A F)$ genes, etc. [13].

Interestingly, molecular signalling in lung cancer and chronic lung diseases often coincides, raising the possibility of a stepwise pathobiology. For example, Wnt pathway genes are known to be upregulated in NSCLC [51], but they are also involved in the pathogenesis of COPD [52]. Wnt signalling induces proliferation of BASCs [53] and this could represent a potential molecular link between emphysema and cancer. Along these lines, several epithelial molecular pathways with prominent roles in lung homeostasis, lung cancer and chronic lung diseases have been described. Indicatively, transforming growth factor (TGF)- $\beta$ signalling underlies asthma, COPD and lung cancer [54-56], hedgehog $(H h)$ signalling can interfere with lung repair and tumorigenesis $[57,58]$, Notch 3 expression regulates basal cell numbers and is involved in COPD and possibly in lung cancer [59,60], while FGF1 signalling can link IPF and lung cancer [50,61]. Of course, additional pathways possibly linking chronic lung diseases and lung cancer include inflammatory signalling caused by tobacco smoke exposure, angiogenic signals and many more that are not in the scope of this mini-review. These signalling pathways, which are commonly involved in the pathogenesis of chronic lung diseases and lung cancer, such as the nuclear factor- $\kappa \mathrm{B}$ pathway which is critically involved in both COPD and lung cancer, are lucrative potential drug targets for the simultaneous enhancement of lung regeneration and prevention of neoplasia $[62,63]$.

\section{Conclusions}

It is becoming increasingly evident that resident airway and alveolar cells display dynamic changes and marked plasticity of gene expression and/or localisation that are cardinal for pulmonary regeneration and neoplasia. Disruption of this homeostatic potential underlies several lung diseases. Therefore, understanding the mechanisms of lung regenerative capacity and elucidating the transcription programmes that are activated during lung repair, disease and carcinogenesis will probably identify novel therapeutic targets.

\section{Acknowledgements}

The authors thank the University of Patras Centre for Animal Models of Disease and Advanced Light Microscopy Facility (Patras, Greece) for experimental support, and their collaborators for insightful discussions on the topic of this review.

\section{References}

1 Lozano R, Naghavi M, Foreman K, et al. Global and regional mortality from 235 causes of death for 20 age groups in 1990 and 2010: a systematic analysis for the Global Burden of Disease Study 2010. Lancet 2012; 380: 2095-2128.

2 Torre LA, Bray F, Siegel RL, et al. Global cancer statistics, 2012. CA Cancer J Clin 2015; 65: 87-108.

3 Fitzmaurice C, Allen C, Barber RM, et al. Global, regional, and national cancer incidence, mortality, years of life lost, years lived with disability, and disability-adjusted life-years for 32 cancer groups, 1990 to 2015: a systematic analysis for the Global Burden of Disease Study. JAMA Oncol 2017; 3: 524-548.

4 Ujiie $\mathrm{H}$, Kadota $\mathrm{K}$, Chaft JE, et al. Solid predominant histologic subtype in resected stage I lung adenocarcinoma is an independent predictor of early, extrathoracic, multisite recurrence and of poor postrecurrence survival. J Clin Oncol 2015; 33: 2877-2884. 
5 Tsao MS, Marguet S, Le Teuff G, et al. Subtype classification of lung adenocarcinoma predicts benefit from adjuvant chemotherapy in patients undergoing complete resection. J Clin Oncol 2015; 33: 3439-3446.

6 Ma J, Ward EM, Smith R, et al. Annual number of lung cancer deaths potentially avertable by screening in the United States. Cancer 2013; 119: 1381-1385.

$7 \quad$ Barnes PJ. Chronic obstructive pulmonary disease. N Engl J Med 2000; 343: 269-280.

8 Gross TJ, Hunninghake GW. Idiopathic pulmonary fibrosis. N Engl J Med 2001; 345: 517-525.

9 Chilosi M, Poletti V, Murer B, et al. Abnormal re-epithelialization and lung remodeling in idiopathic pulmonary fibrosis: the role of $\Delta \mathrm{N}-\mathrm{p} 63$. Lab Invest 2002; 82: 1335-1345.

10 Hogg JC, Paré PD, Hackett TL. The contribution of small airway obstruction to the pathogenesis of chronic obstructive pulmonary disease. Physiol Rev 2017; 97: 529-552.

11 McDonough JE, Yuan R, Suzuki M, et al. Small-airway obstruction and emphysema in chronic obstructive pulmonary disease. N Engl J Med 2011; 365: 1567-1575.

12 Hecht SS. Tobacco smoke carcinogens and lung cancer. J Natl Cancer Inst 1999; 91: 1194-1210.

13 Cancer Genome Atlas Research Network. Comprehensive molecular profiling of lung adenocarcinoma. Nature 2014; 511: 543-550.

14 Westcott PM, Halliwill KD, To MD, et al. The mutational landscapes of genetic and chemical models of Kras-driven lung cancer. Nature 2015; 517: 489-492.

15 Barkauskas CE, Cronce MJ, Rackley CR, et al. Type 2 alveolar cells are stem cells in adult lung. J Clin Invest 2013; 123: 3025-3036.

16 Desai TJ, Brownfield DG, Krasnow MA. Alveolar progenitor and stem cells in lung development, renewal and cancer. Nature 2014; 507: 190-194.

17 Giangreco A, Arwert EN, Rosewell IR, et al. Stem cells are dispensable for lung homeostasis but restore airways after injury. Proc Natl Acad Sci USA 2009; 106: 9286-9291.

18 Giangreco A, Reynolds SD, Stripp BR. Terminal bronchioles harbor a unique airway stem cell population that localizes to the bronchoalveolar duct junction. Am J Pathol 2002; 161: 173-182.

19 Kim CF, Jackson EL, Woolfenden AE, et al. Identification of bronchioalveolar stem cells in normal lung and lung cancer. Cell 2005; 121: 823-835.

20 Zuo W, Zhang T, Wu DZ, et al. $\mathrm{p}^{+} \mathrm{Krt5}^{+}$distal airway stem cells are essential for lung regeneration. Nature 2015; 517: 616-620.

21 Seibold MA, Smith RW, Urbanek C, et al. The idiopathic pulmonary fibrosis honeycomb cyst contains a mucocilary pseudostratified epithelium. PLoS One 2013; 8: e58658.

22 Seibold MA, Wise AL, Speer MC, et al. A common MUC5B promoter polymorphism and pulmonary fibrosis. N Engl J Med 2011; 364: 1503-1512.

23 Imielinski M, Guo G, Meyerson M. Insertions and deletions target lineage-defining genes in human cancers. Cell 2017; 168: 460-472.

24 Sutherland KD, Berns A. Cell of origin of lung cancer. Mol Oncol 2010; 4: 397-403.

25 Giangreco A, Groot KR, Janes SM. Lung cancer and lung stem cells: strange bedfellows? Am J Respir Crit Care Med 2007; 175: 547-553.

26 Hong KU, Reynolds SD, Watkins S, et al. In vivo differentiation potential of tracheal basal cells: evidence for multipotent and unipotent subpopulations. Am J Physiol Lung Cell Mol Physiol 2004; 286: L643-L649.

27 Rawlins EL, Okubo T, Xue Y, et al. The role of Scgbla1 ${ }^{+}$Clara cells in the long-term maintenance and repair of lung airway, but not alveolar, epithelium. Cell Stem Cell 2009; 4: 525-534.

28 Rock JR, Onaitis MW, Rawlins EL, et al. Basal cells as stem cells of the mouse trachea and human airway epithelium. Proc Natl Acad Sci USA 2009; 106: 12771-12775.

29 Zheng D, Limmon GV, Yin L, et al. Regeneration of alveolar type I and II cells from Scgbla1-expressing cells following severe pulmonary damage induced by bleomycin and influenza. PLoS One 2012; 7: e48451.

30 Boers JE, Ambergen AW, Thunnissen FB. Number and proliferation of basal and parabasal cells in normal human airway epithelium. Am J Respir Crit Care Med 1998; 157: 2000-2006.

31 Rock JR, Randell SH, Hogan BL. Airway basal stem cells: a perspective on their roles in epithelial homeostasis and remodeling. Dis Model Mech 2010; 3: 545-556.

32 Volckaert T, De Langhe S. Lung epithelial stem cells and their niches: Fgf10 takes center stage. Fibrogenesis Tissue Repair 2014; 7: 8.

33 Teixeira VH, Nadarajan P, Graham TA, et al. Stochastic homeostasis in human airway epithelium is achieved by neutral competition of basal cell progenitors. Elife 2013; 2: e00966.

34 Lee JH, Bhang DH, Beede A, et al. Lung stem cell differentiation in mice directed by endothelial cells via a BMP4-NFATc1-thrombospondin-1 axis. Cell 2014; 156: 440-455.

35 Tata PR, Mou H, Pardo-Saganta A, et al. Dedifferentiation of committed epithelial cells into stem cells in vivo. Nature 2013; 503: 218-223.

36 Turner J, Roger J, Fitau J, et al. Goblet cells are derived from a FOXJ1-expressing progenitor in a human airway epithelium. Am J Respir Cell Mol Biol 2011; 44: 276-284.

37 Pardo-Saganta A, Law BM, Gonzalez-Celeiro M, et al. Ciliated cells of pseudostratified airway epithelium do not become mucous cells after ovalbumin challenge. Am J Respir Cell Mol Biol 2013; 48: 364-373.

38 Daly HE, Baecher-Allan CM, Paxhia AT, et al. Cell-specific gene expression reveals changes in epithelial cell populations after bleomycin treatment. Lab Invest 1998; 78: 393-400.

39 Pinkerton KE, Dodge DE, Cederdahl-Demmler J, et al. Differentiated bronchiolar epithelium in alveolar ducts of rats exposed to ozone for 20 months. Am J Pathol 1993; 142: 947-956.

40 Meiners S, Eickelberg O, Königshoff M. Hallmarks of the ageing lung. Eur Respir J 2015; 45: 807-827.

41 Seguin L, Kato S, Franovic A, et al. An integrin $\beta_{3}$-KRAS-RalB complex drives tumour stemness and resistance to EGFR inhibition. Nat Cell Biol 2014; 16: 457-468.

42 Cho HC, Lai CY, Shao LE, et al. Identification of tumorigenic cells in Kras(G12D)-induced lung adenocarcinoma Cancer Res 2011; 71: 7250-7258.

43 Mainardi S, Mijimolle N, Francoz S, et al. Identification of cancer initiating cells in K-Ras driven lung adenocarcinoma. Proc Natl Acad Sci USA 2014; 111: 255-260. 
44 Sutherland KD, Song JY, Kwon MC, et al. Multiple cells-of-origin of mutant K-Ras-induced mouse lung adenocarcinoma. Proc Natl Acad Sci USA 2014; 111: 4952-4957.

$45 \mathrm{Xu} \mathrm{X}$, Rock JR, Lu Y, et al. Evidence for type II cells as cells of origin of K-Ras-induced distal lung adenocarcinoma. Proc Natl Acad Sci USA 2012; 109: 4910-4915.

46 Zhang H, Fillmore Brainson C, Koyama S, et al. Lkb1 inactivation drives lung cancer lineage switching governed by polycomb repressive complex 2. Nat Commun 2017; 8: 14922.

$47 \mathrm{Xu}$ X, Huang L, Futtner C, et al. The cell of origin and subtype of K-Ras-induced lung tumors are modified by Notch and Sox2. Genes Dev 2014; 28: 1929-1939.

48 Ischenko I, Zhi J, Moll UM, et al. Direct reprogramming by oncogenic Ras and Myc. Proc Natl Acad Sci USA 2013; 110: 3937-3942.

49 Ferone G, Song JY, Sutherland KD, et al. SOX2 is the determining oncogenic switch in promoting lung squamous cell carcinoma from different cells of origin. Cancer Cell 2016; 30: 519-532.

50 Cancer Genome Atlas Research Network. Comprehensive genomic characterization of squamous cell lung cancers. Nature 2012; 489: 519-525.

51 Stewart DJ. Wnt signaling pathway in non-small cell lung cancer. J Natl Cancer Inst 2014; 106: djt356.

52 Baarsma HA, Skronska-Wasek W, Mutze K, et al. Noncanonical WNT-5A signaling impairs endogenous lung repair in COPD. J Exp Med 2017; 214: 143-163.

53 Zhang Y, Goss AM, Cohen ED, et al. A Gata6-Wnt pathway required for epithelial stem cell development and airway regeneration. Nat Genet 2008; 40: 862-870.

54 Verhamme FM, Bracke KR, Joos GF, et al. Transforming growth factor- $\beta$ superfamily in obstructive lung diseases. More suspects than TGF- $\beta$ alone. Am J Respir Cell Mol Biol 2015; 52: 653-662.

55 Königshoff $M$, Kneidinger N, Eickelberg O. TGF- $\beta$ signaling in COPD: deciphering genetic and cellular susceptibilities for future therapeutic regimen. Swiss Med Wkly 2009; 139: 554-563.

56 Jeon HS, Jen J. TGF- $\beta$ signaling and the role of inhibitory Smads in non-small cell lung cancer. J Thorac Oncol 2010; 5: 417-419.

57 Kugler MC, Joyner AL, Loomis CA, et al. Sonic hedgehog signaling in the lung. From development to disease. Am J Respir Cell Mol Biol 2015; 52: 1-13.

58 Peng T, Frank DB, Kadzik RS, et al. Hedgehog actively maintains adult lung quiescence and regulates repair and regeneration. Nature 2015; 526: 578-582.

59 Tilley AE, Harvey BG, Heguy A, et al. Down-regulation of the notch pathway in human airway epithelium in association with smoking and chronic obstructive pulmonary disease. Am J Respir Crit Care Med 2009; 179: $457-466$

60 Mori M, Mahoney JE, Stupnikov MR, et al. Notch3-Jagged signaling controls the pool of undifferentiated airway progenitors. Development 2015; 142: 258-267.

61 El Agha E, Kosanovic D, Schermuly RT, et al. Role of fibroblast growth factors in organ regeneration and repair. Semin Cell Dev Biol 2016; 53: 76-84.

62 Houghton AM. Mechanistic links between COPD and lung cancer. Nat Rev Cancer 2013; 13: 233-245.

63 Stathopoulos GT, Sherrill TP, Cheng DS, et al. Epithelial NF- $\mathrm{KB}$ activation promotes urethane-induced lung carcinogenesis. Proc Natl Acad Sci USA 2007; 104: 18514-18519. 